\title{
Looking on the bright side: The role of identity status and gender on positive orientations during emerging adulthood
}

\author{
Laura M. Padilla-Walker \\ Brigham Young University - Provo \\ Carolyn McNamara Barry \\ Loyola College in Maryland \\ Jason S. Carroll \\ Brigham Young University - Provo, jcarroll@byu.edu \\ Stephanie D. Madsen \\ McDaniel College \\ Larry J. Nelson

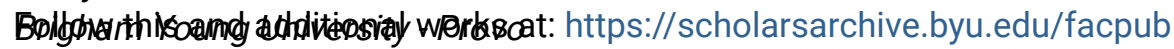 \\ Part of the Other Social and Behavioral Sciences Commons
}

\section{Original Publication Citation}

Padilla-Walker, L. M., Barry, C., Carroll, J. S., Madsen, S. D., \& Nelson, L. J. (2008). Looking on the Bright Side: The Role of Identity Status and Gender on Positive Orientations During Emerging Adulthood. Journal of Adolescence, 31(4), 451-467.

\section{BYU ScholarsArchive Citation}

Padilla-Walker, Laura M.; Barry, Carolyn McNamara; Carroll, Jason S.; Madsen, Stephanie D.; and Nelson, Larry J., "Looking on the bright side: The role of identity status and gender on positive orientations during emerging adulthood" (2007). Faculty Publications. 4341.

https://scholarsarchive. byu.edu/facpub/4341

This Peer-Reviewed Article is brought to you for free and open access by BYU ScholarsArchive. It has been accepted for inclusion in Faculty Publications by an authorized administrator of BYU ScholarsArchive. For more information, please contact ellen_amatangelo@byu.edu. 


\title{
Looking on the bright side: The role of identity status and gender on positive orientations during emerging adulthood
}

\author{
Laura M. Padilla-Walker ${ }^{\mathrm{a}, *}$, Carolyn McNamara Barry ${ }^{\mathrm{b}}$, Jason S. Carroll ${ }^{\mathrm{a}}$, \\ Stephanie D. Madsen ${ }^{c}$, Larry J. Nelson ${ }^{\mathrm{a}}$ \\ a Brigham Young University, 2097 JFSB, School of Family Life, Brigham Young University, Provo, UT 84602, USA \\ ${ }^{\mathrm{b}}$ Department of Psychology, Loyola College in Maryland, Baltimore, MD 21210 \\ ${ }^{\mathrm{c}}$ Department of Psychology, McDaniel College, Westminster, MD 21157
}

\begin{abstract}
Emerging adulthood has been characterized as an age of possibilities that involves heightened identity exploration and risk-taking. Although some scholars have investigated the relation between identity status and risk behaviors in emerging adulthood, less attention has been paid to the relation between identity status and prosocial orientations. Thus, the current study examined how emerging adults' engagement in positive behaviors (i.e., prosocial tendencies, internalization of values, religiosity) varied as a function of identity status and gender. Results indicated that emerging adults who were in identity diffusion reported fewer prosocial tendencies, lower scores on internalization of values and lower religiosity, but emerging adults who were experiencing moratorium reported prosocial tendencies and levels of religiosity as frequently as emerging adults who had reached identity achievement. Also, young women reported higher levels of emotional and altruistic prosocial tendencies, higher levels of internalization of values, and higher levels of religiosity than did young men. The discussion focuses on emerging adulthood as a period of possibilities and exploration for not only risk behaviors, but prosocial behaviors as well.

(C) 2007 The Association for Professionals in Services for Adolescents. Published by Elsevier Ltd. All rights reserved.
\end{abstract}

Keywords: Identity development; Prosocial behaviors; Positive outcomes; Emerging adulthood

\footnotetext{
${ }^{*}$ Corresponding author. Tel.: + 1801422 9053; fax: + 18014220230.

E-mail address: laura_walker@byu.edu (L.M. Padilla-Walker).
}

0140-1971/\$30.00 @ 2007 The Association for Professionals in Services for Adolescents. Published by Elsevier Ltd. All rights reserved.

doi:10.1016/j.adolescence.2007.09.001 


\section{Introduction}

For many young people in contemporary Western societies, the years from the late teens through the early twenties are a time of significant change and importance (Arnett, 2000). Because of the relative diversity in the trajectories of young people during this age period, there is considerable debate surrounding whether the characteristics of this age group represent a developmental period or merely an alternative trajectory (Collins \& Madsen, 2006). Arnett (2000) contends that this age period (which he refers to as emerging adulthood) constitutes a distinct period of the life course for at least a portion of young people in predominantly Western, industrialized societies, and is different in important ways from both adolescence and adulthood. Indeed, unique characteristics of emerging adulthood have been found in China (Nelson, Badger, \& Wu, 2004), in Israel (Mayseless \& Scharf, 2003), and in Argentina (Facio \& Micocci, 2003), as well as among religious minority groups (Barry \& Nelson, 2005).

One of the most notable features of emerging adulthood is the opportunity it provides for identity exploration, particularly in the areas of love, work, and worldviews (Arnett, 2000). As a result of demographic shifts in postindustrial societies, some individuals in their late teens through the twenties, particularly those who are able to attend college instead of beginning fulltime employment, marriage or parenthood roles, have few responsibilities compared to later in the lifespan. This allows for ample time to question values, laws, beliefs, norms, or standards; or to engage in experimentation with possible roles, a process of identity exploration first begun in adolescence (Erikson, 1968). The literature predominantly has documented the assorted risk behaviors of emerging adults (e.g., binge drinking, unprotected sex, illegal drug use; e.g., Schulenberg, O'Malley, Bachman, \& Johnston, 2005), but considerably less attention has been paid to emerging adults' positive orientations, and how the levels of and type of engagement with positive orientations might vary as a function of identity status and gender. Given that identity exploration and commitment have been associated with the achievement of adulthood criteria, and that self-perceived adults engage in fewer risk behaviors (Nelson \& Barry, 2005) and are oriented more towards consideration of others (Nelson et al., in press), in addition to research suggesting gender differences in prosocial outcomes (Carlo \& Randall, 2002), it follows that the frequency of positive orientations should vary as a function of one's identity status and gender.

\section{Positive orientations}

Although it has been documented that emerging adults often engage in assorted risk behaviors (Schulenberg \& Zarrett, 2006), it is likely that they also engage in a variety of positive behaviors. In the current study, we sought to examine a more global orientation towards positive behavior by focusing on three indicators of positive orientation: prosocial behavioral tendencies, internalization of prosocial values, and religious faith. Given that current research on emerging adults focuses primarily on behavior that is potentially harmful to self (e.g., substance use, risky sexuality) or others (e.g., drunk/risky driving), we sought to highlight behavior or tendencies that are meant to benefit others. Prosocial behavioral tendencies (defined as behavioral tendencies meant to benefit another), internalization of prosocial values, and religiosity are all indicators assessing the potential underlying beliefs that support the display of positive behaviors, and 
research has found these three constructs to be conceptually and empirically interrelated (Hardy \& Carlo, 2005). Indeed, research has found that prosocial tendencies (Carlo \& Randall, 2002), prosocial values (Padilla-Walker \& Carlo, in press), and religiosity (Pedersen, Williams, \& Kristensen, 2000) are all related to positive behavioral outcomes, making these constructs viable indicators of an overall positive orientation.

\section{Prosocial behavioral tendencies}

As a result of advances in social cognition (e.g., empathy, perspective-taking skills), a greater focus on interpersonal relationships, and changes in the social context, the venues for displaying prosocial behaviors increase substantially from adolescence onward, and the variety of prosocial behaviors increases as well (e.g., Fabes, Carlo, Kupanoff, \& Laible, 1999). In fact, the overwhelming majority of emerging adults maintain that "developing greater consideration for others" (an indicator of prosocial tendencies) is necessary for one to be considered an adult (Mayseless \& Scharf, 2003). Thus, emerging adults' display of prosocial behaviors appears to serve as an indicator of a positive developmental trajectory for the transition to adulthood. Since high levels of identity exploration and commitment have been associated with self-perceived status as an adult (Nelson \& Barry, 2005), and this self-perceived adult status is highly dependent upon positive orientations (e.g., consideration for others, less self-focus), it follows that the extent to which emerging adults display prosocial behaviors should vary as a function of their identity status, as conceptualized by Marcia (1966). Despite the vast amount of literature on identity status in general (Kroger, 2000), we are aware of no research that has examined the relations between identity status and prosocial behavioral tendencies.

Historically, scholars have examined prosocial behavior as a global construct, but more recently have begun to examine numerous situation-specific types of prosocial behaviors, which are referred to as prosocial tendencies (Carlo \& Randall, 2002). As reviewed by Eisenberg and Fabes (1998), notable individual differences in types of prosocial tendencies have been documented in the literature, such that individuals who display high levels of altruistic tendencies report particularly high levels of moral reasoning and exhibit little aggression, whereas individuals who display prosocial tendencies primarily in public forums report high levels of approval-oriented prosocial moral reasoning (Carlo \& Randall, 2002). Investigating prosocial behavioral tendencies in a situation-specific manner thereby reveals a more complete picture of one form of emerging adults' positive orientation. The six prosocial tendencies examined in the current study included public (i.e., helping others in front of an audience, motivated largely by approval), emotional (i.e., helping others who are in emotionally evocative situations), dire, (i.e., helping in a crisis), anonymous (i.e., helping others without their knowledge), altruistic (i.e., helping others with little regard for self-consequences), and compliant (i.e., helping others when asked).

In addition, gender differences with global measures of prosocial behaviors have traditionally found girls and young women to score uniformly higher on prosocial behaviors than do boys and young men (see Eisenberg \& Fabes, 1998); however, the pattern is not as uniform when situationspecific types of prosocial behaviors are used. For instance, adolescent boys report more public prosocial tendencies, whereas adolescent girls report more emotional and altruistic prosocial tendencies (Carlo, Hausmann, Christiansen, \& Randall, 2003). As a result, in the current study we 
examined how situation-specific prosocial behavioral tendencies varied as a function of both identity statuses and gender.

\section{Internalization of values}

The motivation to display prosocial behavior, in part, stems from an individual's need to remain steadfast to his or her prosocial values (Eisenberg, Cumberland, Guthrie, Murphy, \& Shepard, 2005). The process of internalizing one's values, in this case prosocial values, involves a shift of values from an external source of control or motivation to an internal source (see Grolnick, Deci, \& Ryan, 1997). The conceptualization of internalization of values in the current paper was based on self-determination theory, which suggests that internalization occurs on a continuum ranging from external regulation (Level 1), where motivation stems entirely from external forces, such as avoiding punishment; to introjected regulation (Level 2), where motivation is internal but is still motivated by control from external sources, such as approval or guilt; to identified regulation (Level 3), where motivation is internal and autonomous, such that holding true to the value is a personal goal for a particular situation, and is done because it is internally satisfying; to integrated regulation (Level 4), where motivation is internal and autonomous, but applies to multiple aspects of one's life as opposed to a single situation (Grolnick et al., 1997).

Few studies have examined the internalization of prosocial values empirically, and we are aware of no previous research that has examined internalization of values as a function of identity status. However, research has found that other cognitions, such as racist beliefs, vary as a function of identity status (Fulton, 1997). The few studies examining prosocial values internalization have found no gender differences in adolescents' levels of internalization of values (e.g., Hardy, PadillaWalker, \& Carlo, 2007), but research suggests that gender differences in self-reported positive orientations increase with age (possibly due to societal expectations for girls and women to engage in more positive behaviors). Thus, we examined whether one's scores on the four levels of internalization of values varied by one's identity status and gender.

\section{Religiosity}

As part of heightened exploration concerning worldviews (Arnett, 2000), emerging adults report giving considerable thought to their religious beliefs (Arnett \& Jensen, 2002). Despite these relatively high levels of exploration concerning beliefs, emerging adults typically report relatively low levels of religious participation compared to other age groups (Gallup \& Lindsay, 1999). Instead, other dimensions of religiosity, namely their faith or beliefs about religion, are salient to many emerging adults. Given the documented findings that high levels of intrinsic and extrinsic religious orientation are associated with lower rates of risk behaviors (i.e., sexual risk-taking behavior; Zaleski \& Schiaffino, 2000), and high levels of other religiosity indicators (i.e., religious importance, emotional religion index, and spirituality importance) are associated with selfreported prosocial behaviors (e.g., Saroglou, Pichon, Trompette, Verschueren, \& Dernelle, 2005), religiosity in emerging adulthood is an important area of investigation to understand factors that contribute to positive orientations.

Scholars have examined how religiosity varies as a function of identity status. For instance, identity-foreclosed and achieved emerging adults have been shown to report high levels of 
religious faith maturity (Sanders, 1998), whereas identity-diffused college students reported little emphasis on moral and religious issues in their families (Willemsen \& Waterman, 1991). In addition, students from a public university were more likely to be identity-achieved if they frequently prayed and reported being committed to their religion (McKinney \& McKinney, 1999). Moreover, women consistently report higher levels of various dimensions of religiosity such as religious importance (Koenig, McCullough, \& Larson, 2001) and the cognition of religion (Neitz, 1995) than do men. Thus in the current study, the strength of religious faith was investigated as a function of identity status and gender.

\section{Hypotheses}

Given research on the relation between identity statuses and risk behaviors (Bishop, Macy-Lewis, Schnekloth, Puswella, \& Struessel, 1997) as well as positive outcomes (Sanders, 1998), we posited that emerging adults who reported higher levels of identity exploration (i.e., achieved and moratorium) or higher levels of commitment (i.e., foreclosed and achieved; see Nelson \& Barry, 2005) would report high levels of the three positive orientations (i.e., prosocial behavioral tendencies, internalization of prosocial values, and religiosity), whereas emerging adults who reported lower levels of identity exploration and commitment (i.e., diffused or foreclosed) would report lower levels of positive orientations. Given the existing literature on identity-foreclosed and achieved adults and religiosity (Kiesling, Sorell, Montgomery, \& Colwell, 2006; McKinney \& McKinney, 1999), it also was expected that they would report higher levels of religiosity than would those in identity moratorium. Additionally, gender differences were explored in these positive orientations. Based on existing research (Carlo \& Randall, 2002), we expected that men would report higher levels of public prosocial tendencies and women would report higher levels of emotional and altruistic tendencies; we expected no gender differences in other tendencies. Based on existing research on adolescence, we expected no gender differences as a function of internalization of values (Padilla-Walker, 2005), but expected women to report higher levels of religiosity than would men (Koenig et al., 2001).

\section{Method}

\section{Participants}

Participants for this study were drawn from a study of emerging adults and their parents entitled "Project READY" (Researching Emerging Adults' Developmental Years). This project is a collaborative, multi-site study that is being conducted by a consortium of developmental and family scholars. The sample used in the current study consisted of 491 undergraduate and graduate students (282 women, 209 men) recruited from five college sites (a small, private liberal arts college and a medium-sized, religious university on the East coast; two large, Midwestern public universities; and a large, public university on the West coast). Response rate varied by site (ranging from $50 \%$ to $75 \%$ ), with an overall response rate of approximately $63 \%$. The mean age of the sample was 20.10 years $(S D=1.86$, range $=18-25)$. Seventy-five percent of the participants were European American, 2\% were African American, 12\% were Asian American, $4 \%$ were Latino American, and $7 \%$ indicated that they were "mixed/biracial" or of an other 
ethnicity. Participants reported a variety of religious affiliations: Roman Catholic, 31\%; Conservative Christian, 21\%; Liberal Christian, 15\%; other faiths (e.g., Jewish, Greek Orthodox), 4\%; Atheist/Agnostic, 9\%; and no affiliation, 20\%. Ninety percent of emerging adults reported living outside of their parents' home in an apartment, house, or residence hall. Ten percent reported living in their parents' home. Only $10 \%$ of emerging adults reported being financially independent of their parents, with the majority of participants $(75 \%)$ reporting making a personal income of $\$ 5000$ or less per year. From the subset of the selected sample whose parents participated $(68 \%), 14 \%$ of parents reported a yearly income less than $\$ 50,000,13 \%$ reported a yearly income between $\$ 50,000$ and $\$ 75,000,20 \%$ reported a yearly income between $\$ 75,000$ and $\$ 100,000$, and $50 \%$ reported a yearly income over $\$ 100,000$.

\section{Procedure}

Participants completed the Project READY questionnaire via the Internet (see http://www. projectready.net). The use of an online data collection protocol facilitated unified data collection across multiple university sites and allowed for the survey to be administered to emerging adults and their parents (parent participation was not required) who were living in separate locations throughout the country (parent data were not used in this study). After receiving IRB approval from all five sites, participants were recruited through faculty's announcement of the study in undergraduate and graduate courses. Undergraduate courses were primarily Introduction to Psychology courses or large general education courses of the like in an attempt to access a broad range of students. Professors at the various universities were provided with a student handout that had a brief explanation of the study and directions for accessing the online survey. Interested students then accessed the study website with a location-specific recruitment code. Informed consent was obtained online, and only after consent was given could the participants begin the questionnaires. Each participant was asked to complete a survey battery of 448 items. Sections of the survey addressed topic areas such as background information, family-of-origin experiences, self-perceptions, personality traits, values, risk behaviors, dating behaviors, prosocial tendencies, and religiosity. Most participants were offered course/extra credit for their participation. In a small number of cases $(\approx 5 \%)$, participants were offered small monetary compensation (i.e., $\$ 10$ gift certificates) for their participation.

A number of analyses were conducted to determine if outcome variables or participant demographics differed as a function of data collection site. Two multivariate analyses of variance (MANOVAs) were conducted to examine prosocial tendencies and internalization of values, ANOVAs were used to examine religiosity, age, and income, and $\chi^{2}$ analyses were conducted to examine identity status, gender, and ethnicity. The only significant difference found was a $\chi^{2}$ for ethnicity, with more Asian Americans from the West Coast site than from the Midwestern or East Coast sites, $\chi^{2}(12)=27.94, p<.01$. No additional significant differences were found between sites on the variables of interest; thus, data were collapsed across sites.

\section{Measures}

For the current study we examined emerging adults' reports of identity status, prosocial behavioral tendencies, internalization of value, and religiosity. 


\section{Identity status}

Identity status was assessed using a shortened version of the Ego Identity Process Questionnaire (Balistreri, Busch-Rossnagel, \& Geisinger, 1995), which considers 20 statements regarding individuals' commitment and exploration on various aspects of identity, including occupation, religion, values, family, and dating. Sample items include, "I have definitely decided on the occupation I want to pursue" for commitment, and "I am not quite sure about what type of dating relationship is best for me" for exploration. Participants rated each statement on a 6-point scale with values ranging from 1 (strongly disagree) to 6 (strongly agree). Scoring was reversed for negatively-worded items, and item scores were summed to obtain total scores for identity commitment and identity exploration, both of which could range from 10 to 60 . After calculating the scores for the identity commitment $(\alpha=.69)$ and identity exploration $(\alpha=.60)$ subscales, median splits were computed for each (for identity commitment, median $=41.00$; for identity exploration, median $=39.00$ ) ; given the shortened measure, the internal consistency values were in keeping with findings by Balistreri et al. (1995). As suggested by Balistreri and colleagues, each individual then was categorized into one of four possible identity statuses. Specifically, identity achievement signified participants with both identity exploration $(M=44.94, S D=3.20)$ and commitment $(M=47.39, S D=3.91)$ scores above the median $(15 \%$ of sample; $12 \%$ of men, $16 \%$ of women); identity foreclosure signified participants with identity exploration $(M=35.29$, $S D=4.01)$ scores below the median, but identity commitment $(M=47.79, S D=3.79)$ scores above the median ( $28 \%$ of the sample; $25 \%$ of men, $30 \%$ of women); identity moratorium signified participants with identity exploration $(M=45.10, S D=3.76)$ scores above the median, but identity commitment $(M=36.54, S D=4.14)$ scores below the median $(23 \%$ of the sample; $21 \%$ of men, $24 \%$ of women); and identity diffusion signified participants with both identity exploration $(M=35.67, S D=3.89)$ and commitment $(M=36.81, S D=3.84)$ scores below the median (35\% of the sample; $42 \%$ of men, $30 \%$ of women). A $\chi^{2}$ analysis was conducted to determine if identity status was significantly different as a function of gender, and it was not significant, $X^{2}(3)=7.60$, ns.

\section{Prosocial behavioral tendencies}

Prosocial tendencies were assessed using the Prosocial Tendencies Measure (PTM), which has been used in the past with both adolescents and emerging adults, and has displayed adequate internal reliability and validity (Carlo et al., 2003; Carlo \& Randall, 2002). Although this measure does not assess the frequency of prosocial behaviors directly, it is designed to measure tendencies toward different types of prosocial behaviors, and is correlated with global frequency of prosocial behaviors (Carlo \& Randall, 2002). This 25-item measure is composed of six subscales: public (4 items, $\alpha=.87$, sample item, "I can help others best when people are watching me"), emotional ( 5 items, $\alpha=.85$, sample item, "I tend to help others particularly when they are emotionally distressed"), dire ( 3 items, $\alpha=.79$, sample item, "I tend to help people who are in real crisis or need"), anonymous ( 5 items, $\alpha=.84$, sample item, "I tend to help others in need when they do not know who helped them"), altruistic ( 6 items, $\alpha=.76$, sample item, "I often help even if I don't think I will get anything out of helping"), and compliant (2 items, $\alpha=.69$, sample item, "When people ask me to help them, I don't hesitate"). For each subscale, participants responded on a scale ranging from 1 (does not describe me at all) to 5 (describes me greatly). 


\section{Internalization of values}

Values internalization was assessed using a 28-item measure adapted from the Prosocial Self-Regulation Questionnaire (Ryan \& Connell, 1989). This measure has been used in the past with adolescents, and has displayed adequate internal reliability and validity (Hardy et al., 2007; Padilla-Walker, 2005). Participants responded to questions regarding kindness, honesty, and fairness values, with seven items assessing each level of values internalization: external (e.g., "I am kind to others because I want people to think I'm a kind person"), introjected (e.g., "I am kind to others because my friends or parents would be disappointed if I wasn't kind"), identified (e.g., "I am kind to others because it feels good to be kind"), and integrated (e.g., "I am kind to others because it is important to me to be a kind person"). Participants responded to statements on a scale ranging from 1 (not at all true) to 4 (very true). Scores were averaged within each level, and Cronbach's alphas for Level 1 (external), 2 (introjected), 3 (identified), and 4 (integrated) were $.87, .90, .83$, and .80 , respectively.

\section{Religious faith}

Religiosity was assessed using the Santa Clara Strength of Religious Faith Questionnaire (Lewis, Shevlin, McGuckin, \& Navrátil, 2001), which is a well-established measure that has demonstrated adequate reliability and validity with adolescent and adult populations. Participants responded to 10 items regarding their religious faith regardless of religious denomination or affiliation (e.g., "My religious faith is extremely important to me," "I look to my faith as providing meaning and purpose in my life") on a Likert-type scale ranging from 1 (strongly disagree) to 4 (strongly agree). Items were averaged with higher scores representing higher self-reported religious faith $(\alpha=.98)$.

\section{Results}

\section{Descriptive statistics and correlations among study variables}

A univariate analysis of variance (ANOVA) was conducted to determine if identity status varied as a function of the age of the emerging adult, and it was statistically significant, $F(3,484)=5.85, p<.01$. Posthoc comparisons using Fisher's Least Significant Difference (LSD) revealed that individuals with a diffused identity were younger $(M=19.72, S D=1.70)$ than were individuals who were identity-achieved $(M=20.71, S D=2.05)$, foreclosed $(M=20.13, S D=1.80)$, or in moratorium $(M=20.14, S D=1.93)$. A number of correlations also were conducted to see if age was related to any of the dependent variables, and age was related negatively to external values regulation $(r=-.10, p<.05)$ and related negatively to religious faith $(r=-.08, p<.05)$. Thus, we controlled for the age in the remaining analyses.

Table 1 contains descriptive statistics, as well as correlations between the dependent variables assessing positive orientations. It should be noted that most indicators of positive orientation were correlated with one another, but not strongly enough to warrant analyzing all three outcomes together. Thus, we examined prosocial tendencies, internalization of values, and religious faith as separate outcomes in all analyses. 
Table 1

\begin{tabular}{|c|c|c|c|c|c|c|c|c|c|c|c|}
\hline Variable scale & 1 & 2 & 3 & 4 & 5 & 6 & 7 & 8 & 9 & 10 & 11 \\
\hline 1. Public prosocial tendencies & - & & & & & & & & & & \\
\hline 2. Emotional prosocial tendencies & .03 & - & & & & & & & & & \\
\hline 3. Dire prosocial tendencies & .06 & $.64^{* *}$ & - & & & & & & & & \\
\hline 4. Anonymous prosocial tendencies & $.12 * *$ & $.23 * *$ & $.28^{* *}$ & - & & & & & & & \\
\hline 5. Altruistic prosocial tendencies & $-.64 * *$ & .07 & .03 & .02 & - & & & & & & \\
\hline 6. Compliant prosocial tendencies & -.04 & $.50 * *$ & $.50 * *$ & $.27 * *$ & $.15^{* *}$ & - & & & & & \\
\hline 7. Level 1 - external regulation & $.35^{* *}$ & $.13^{* *}$ & $.10^{*}$ & .03 & $-.25 * *$ & $.16^{* *}$ & - & & & & \\
\hline 8. Level 2-introjected regulation & $.28 * *$ & $.14^{* *}$ & $.09^{*}$ & $.12 *$ & $-.23^{* *}$ & $.11 *$ & $.74^{* *}$ & - & & & \\
\hline 9. Level 3-identified regulation & $-.09 *$ & $.32 * *$ & $.21 * *$ & $.23 * *$ & $.23^{* *}$ & $.37 * *$ & $.41 * *$ & $.42 * *$ & - & & \\
\hline 10. Level 4 -integrated regulation & $-.18^{* *}$ & $.33^{* *}$ & $.28^{* *}$ & $.27^{* *}$ & $.34 * *$ & $.42 * *$ & $.29^{* *}$ & $.30^{* *}$ & $.78^{* *}$ & - & \\
\hline 11. Religious faith & -.02 & .07 & .04 & $.22 * *$ & $.09 *$ & $.12 *$ & .09 & $.14 * *$ & $.21 * *$ & $.30 * *$ & - \\
\hline$N$ & 491 & 485 & 489 & 483 & 487 & 490 & 489 & 491 & 489 & 490 & 490 \\
\hline Minimum & 1.00 & 1.00 & 1.00 & 1.00 & 1.67 & 1.00 & 1.00 & 1.00 & 1.00 & 1.00 & 1.00 \\
\hline Maximum & 5.00 & 5.00 & 5.00 & 5.00 & 5.00 & 5.00 & 4.00 & 4.00 & 4.00 & 4.00 & 4.00 \\
\hline M & 1.80 & 3.64 & 3.55 & 2.75 & 4.03 & 3.72 & 2.87 & 2.75 & 3.40 & 3.47 & 2.63 \\
\hline$S D$ & .81 & .81 & .87 & .89 & .70 & .85 & .66 & .70 & .53 & .46 & .93 \\
\hline
\end{tabular}

${ }^{*}$ Correlation is significant at the $p=.05$ level (2-tailed). ${ }^{* *}$ Correlation is significant at the $p=.01$ level (2-tailed). 


\section{Emerging adults' positive orientations as a function of gender and identity status}

\section{Prosocial tendencies}

A multivariate analysis of covariance (MANCOVA) was conducted to determine differences between groups in their prosocial tendencies. The independent variables were gender (men and women) and identity status (achieved, foreclosed, moratorium, and diffused), and the control variable was age. Positive outcomes included public, emotional, dire, anonymous, altruistic, and compliant prosocial tendencies. Means and standard deviations for these variables are presented in Table 2. The main effects for gender, $F(6,459)=4.59, p<.001$, partial $e_{t a}{ }^{2}=.06$, and identity, $F(18,1383)=4.38, p<.001$, partial $e t a^{2}=.06$, were statistically significant. The interaction between gender and identity was not significant. LSD posthoc comparisons revealed that young men reported higher public prosocial tendencies than did young women, and young women reported higher emotional and altruistic prosocial tendencies than did young men. In regard to identity status, posthoc comparisons suggested that individuals with a diffused identity status reported higher public prosocial tendencies than did individuals with any other identity status, and reported lower emotional, dire, altruistic, and compliant prosocial tendencies than did individuals with any other identity status. Identity-achieved individuals reported higher altruistic prosocial tendencies than did identity-foreclosed or diffused, and those in identity moratorium did not differ on altruistic tendencies from those with an achieved or a foreclosed status.

\section{Internalization of values}

A MANCOVA was conducted to determine differences between groups in level of internalization of values. The independent variables were gender (men and women) and identity status (achieved, foreclosed, moratorium, and diffused), and the control variable was age. Outcomes included the four levels of internalization of values (external, introjected, identified, and

Table 2

Emerging adults' prosocial tendencies as a function of gender and identity status

\begin{tabular}{|c|c|c|c|c|c|c|c|c|c|c|}
\hline & \multicolumn{4}{|l|}{ Gender } & \multicolumn{6}{|c|}{ Identity status } \\
\hline & $\begin{array}{l}\text { Young men } \\
n=205\end{array}$ & $\begin{array}{l}\text { Young women } \\
n=270\end{array}$ & & & $\begin{array}{l}\text { Achieved } \\
n=68\end{array}$ & $\begin{array}{l}\text { Foreclosed } \\
n=133\end{array}$ & $\begin{array}{l}\text { Moratorium } \\
n=108\end{array}$ & $\begin{array}{l}\text { Diffused } \\
n=166\end{array}$ & & \\
\hline & $M(S D)$ & $\mathrm{M}(S D)$ & $E t a^{2}$ & $F^{1}$ & $M(S D)$ & $M(S D)$ & $\mathrm{M}(S D)$ & $M(S D)$ & $E t a^{2}$ & $F^{2}$ \\
\hline \multicolumn{11}{|c|}{ Prosocial tendencies } \\
\hline Public & $1.98(.87)$ & $1.67(.74)$ & .02 & $8.79 * *$ & $1.57(.55)_{\mathrm{a}}$ & $1.78(.86)_{\mathrm{a}}$ & $1.64(.73)_{\mathrm{a}}$ & $2.01(.86)_{\mathrm{b}}$ & .04 & $6.30 * * *$ \\
\hline Emotional & $3.51(.83)$ & $3.74(.79)$ & .01 & $4.72 *$ & $3.81(.87)_{\mathrm{a}}$ & $3.78(.68)_{\mathrm{a}}$ & $3.80(.88)_{\mathrm{a}}$ & $3.35(.78)_{\mathrm{b}}$ & .07 & $10.11 * * *$ \\
\hline Dire & $3.57(.85)$ & $3.55(.89)$ & .01 & 1.48 & $3.78(.88)_{\mathrm{a}}$ & $3.72(.85)_{\mathrm{a}}$ & $3.69(.88)_{\mathrm{a}}$ & $3.25(.79)_{\mathrm{b}}$ & .07 & $11.65^{* * *}$ \\
\hline Anonymous & $2.75(.91)$ & $2.75(.88)$ & .00 & .13 & $2.84(.74)$ & $2.80(.97)$ & $2.73(.98)$ & $2.69(.93)$ & .01 & .56 \\
\hline Altruistic & $3.87(.75)$ & $4.15(.62)$ & .02 & $10.00 * * *$ & $4.30(.66)_{\mathrm{a}}$ & $4.10(.69)_{\mathrm{b}}$ & $4.12(.65)_{\mathrm{ab}}$ & $3.80(.67)_{\mathrm{c}}$ & .06 & $9.53 * * *$ \\
\hline Compliant & $3.62(.87)$ & $3.79(.82)$ & .01 & .82 & $3.92(.79)_{\mathrm{a}}$ & $3.94(.83)_{\mathrm{a}}$ & $3.76(.84)_{\mathrm{a}}$ & $3.43(.85)_{\mathrm{b}}$ & .07 & $10.68 * * *$ \\
\hline
\end{tabular}

$* p<.05, * * p<.01, * * * p<.001$.

Note: Means in the same row with differing letters are significantly different from one another based on LSD posthoc analyses.

${ }^{1}$ Degrees of freedom for prosocial behaviors by gender were 1 .

${ }^{2}$ Degrees of freedom for prosocial behaviors by identity were 3 . 
integrated). Means and standard deviations for all of these variables are presented in Table 3 . The main effects for gender, $F(4,475)=9.81, p<.001$, partial $e t a^{2}=.08$, and identity, $F(12,1431)=5.99, p<.001$, partial $e t a^{2}=.05$, were statistically significant. The interaction between gender and identity was not significant. LSD posthoc comparisons revealed that young women reported higher levels of internalization of values than did young men for all four levels of internalization. Posthoc comparisons suggested that individuals with an achieved identity status reported the highest scores on identified and integrated (Levels 3 and 4) internalization, and individuals with a diffused identity status reported the lowest scores on identified and integrated internalization. Individuals in moratorium did not differ from foreclosed individuals on identified and integrated internalization, and there were no differences as a function of identity status for external and introjected regulation (Levels 1 and 2).

\section{Religiosity}

A univariate analysis of covariance (ANCOVA) was conducted to determine differences between groups in the strength of religious faith. The independent variables were gender (men and women) and identity status (achieved, foreclosed, moratorium, and diffused), and the control variable was age. Religious faith was the outcome variable. Means and standard deviations for all of these variables are presented in Table 3 . The main effects for gender, $F(1,482)=4.55, p<.05$, partial $e t a^{2}=.01$, and identity, $F(3,482)=4.73, p<.01$, partial $e t a^{2}=.03$, were statistically significant. The interaction between gender and identity was not significant. LSD posthoc

Table 3

Emerging adults' internalization of values and religiosity as a function of gender and identity status

\begin{tabular}{|c|c|c|c|c|c|c|c|c|c|c|}
\hline & \multicolumn{4}{|l|}{ Gender } & \multicolumn{6}{|l|}{ Identity status } \\
\hline & $\begin{array}{l}\text { Young men } \\
n=207\end{array}$ & $\begin{array}{l}\text { Young women } \\
n=279\end{array}$ & & & $\begin{array}{l}\text { Achieved } \\
n=72\end{array}$ & $\begin{array}{l}\text { Foreclosed } \\
n=136\end{array}$ & $\begin{array}{l}\text { Moratorium } \\
n=111\end{array}$ & $\begin{array}{l}\text { Diffused } \\
n=167\end{array}$ & & \\
\hline & $M(S D)$ & $\mathrm{M}(S D)$ & $E t a^{2}$ & $F^{1}$ & $M(S D)$ & $M(S D)$ & $\mathrm{M}(S D)$ & $M(S D)$ & $E t a^{2}$ & $F^{2}$ \\
\hline \multicolumn{11}{|c|}{ Internalization of values } \\
\hline $\begin{array}{l}\text { Level 1: } \\
\text { External }\end{array}$ & $2.78(.66)$ & $2.92(.64)$ & .02 & $7.57 * *$ & $2.88(.67)$ & $2.91(.67)$ & $2.82(.64)$ & $2.84(.64)$ & .00 & .27 \\
\hline $\begin{array}{l}\text { Level 2: } \\
\text { Introjected }\end{array}$ & $2.63(.71)$ & $2.84(.69)$ & .03 & $12.15^{* * *}$ & $2.75(.73)$ & $2.77(.74)$ & $2.72(.69)$ & $2.75(.67)$ & .00 & .25 \\
\hline $\begin{array}{l}\text { Level 3: } \\
\text { Identified }\end{array}$ & $3.22(.57)$ & $3.54(.45)$ & .07 & $37.98 * * *$ & $3.58(.53)_{\mathrm{a}}$ & $3.50(.41)_{\mathrm{ab}}$ & $3.41(.54)_{\mathrm{b}}$ & $3.24(.56)_{\mathrm{c}}$ & .05 & $7.04 * * *$ \\
\hline $\begin{array}{l}\text { Level 4: } \\
\text { Integrated }\end{array}$ & $3.33(.50)$ & $3.58(.40)$ & .05 & $23.94 * * *$ & $3.75(.32)_{\mathrm{a}}$ & $3.54(.34)_{\mathrm{ab}}$ & $3.52(.41)_{\mathrm{b}}$ & $3.27(.54)_{\mathrm{c}}$ & .12 & $20.87 * * *$ \\
\hline & $n=209$ & $n=281$ & & & $n=72$ & $n=135$ & $n=112$ & $n=171$ & & \\
\hline $\begin{array}{l}\text { Religious } \\
\text { faith }\end{array}$ & $2.51(.90)$ & $2.71(.95)$ & .01 & $4.44 *$ & $2.69(1.06)_{\mathrm{ab}}$ & $2.88(.89)_{\mathrm{a}}$ & $2.55(.95)_{\mathrm{b}}$ & $2.46(.85)_{\mathrm{b}}$ & .03 & $4.73 * *$ \\
\hline
\end{tabular}

$* p<.05, * * p<.01, * * * p<.001$.

Note. Means in the same row with differing letters are significantly different from one another based on LSD posthoc analyses.

${ }^{1}$ Degrees of freedom for internalization by gender were 1 .

${ }^{2}$ Degrees of freedom for internalization by identity were 3 . 
comparisons revealed that young women reported higher levels of religiosity than did young men. In regard to identity status, posthoc comparisons suggested that individuals with a foreclosed identity reported higher levels of religiosity than did individuals in moratorium or identity diffusion, and individuals in moratorium or identity diffusion did not differ in level of religiosity from those who were identity-achieved.

\section{Discussion}

The current study examined how emerging adults' positive orientations varied as a function of identity status and gender. Findings suggested that identity-diffused emerging adults were less likely to report high levels of prosocial values internalization and religiosity, whereas identityachieved emerging adults reported the highest levels on these variables. Identity-foreclosed emerging adults reported greater strength of religious faith than did those in identity moratorium or diffusion. Thus, findings were generally consistent with hypotheses, and suggest that emerging adulthood, for many individuals, is not only a time of exploring risk behaviors, but is also a time of exploring positive tendencies, values, and beliefs.

\section{Positive orientations and identity status}

The current study found two notable results in investigating the role of emerging adults' positive exploration. First, emerging adults with a diffused identity reported lower levels of prosocial tendencies (with the exception of public prosocial tendencies, which were higher for those with a diffused identity, and anonymous prosocial tendencies which did not differ by identity status), and lower scores on identified and integrated internalization of values (Levels 3 and 4), than did emerging adults in any other identity status. This extends research suggesting that identity diffusion is a period of neither exploration nor commitment, and suggests that not only are these individuals engaging in the highest level of risk behaviors as illustrated by previous work (e.g., Welton \& Houser, 1997), but they are also engaging in the lowest level of prosocial behavioral tendencies (i.e., only helping others when one stands to benefit from public recognition). This may be indicative of high levels of self-focus and an inability to balance self-interests with that of others, a necessary ingredient for adult roles such as marriage (Carroll et al., 2007).

The second notable result in regard to identity status was that there were no other group differences in the frequency of reported prosocial behavioral tendencies as a function of identity status, and individuals in identity moratorium did not differ in religiosity from individuals who were identity-achieved. In other words, emerging adults who were experiencing moratorium also were reporting prosocial tendencies and levels of religious faith as frequently as emerging adults who had reached identity achievement. Thus, those in identity moratorium are perhaps testing out prosocial orientations as part of their exploration, and are thus exhibiting an other-centered focus (Carroll et al., 2007), which is suggestive of behaving more like an adult. These findings suggest that, with the exception of individuals with a diffused identity status, it is likely that regardless of one's level of exploration or commitment, prosocial tendencies and religious faith are central to the emerging adulthood period, even if emerging adults are simultaneously exploring relatively 
normative risk behaviors. This is consistent with research suggesting the importance of religious beliefs during emerging adulthood (Arnett \& Jensen, 2002), and extends this research to prosocial tendencies as well. Although emerging adults experiencing moratorium reported lower levels of identified and integrated internalization of values (Levels 3 and 4) than did emerging adults who were identity-achieved, they also reported higher levels of values internalization than did individuals who were identity-diffused. Taken together, this adds to research suggesting that emerging adults are involved in experimentation with risk behaviors (Schulenberg \& Zarrett, 2006) by suggesting that this is also a time period characterized by the exploration and experimentation of positive roles and orientations.

The finding that identity-foreclosed emerging adults reported the highest levels of religiosity is consistent with existing literature (e.g., Kiesling et al., 2006; Sanders, 1998), and could be explained by the fact that identity-foreclosed emerging adults tend to report an absence of family conflict, which in turn may facilitate their willingness to be socialized in their parents' values and beliefs as compared to other identity statuses such as identity-diffused individuals who have reported little emphasis within their families on religious socialization (Willemsen \& Waterman, 1991). While identity-achieved emerging adults reported significantly higher religiosity than did identity-diffused, it is surprising that they did not differ statistically from those in identity moratorium. Certainly using a specific indicator of religiosity, strength of religious faith (albeit a psychometrically sound measure) rather than other aspects of religiosity (e.g., religious practices, orientation) as well as spirituality (i.e., beliefs that are not specific to an organized religious institution and/or doctrine) might have affected the results. Clearly, future work needs to use a variety of religious and spiritual measures to tease apart the role of identity status in the display of positive behaviors.

Although research on emerging adulthood suggests that this period in life is characterized by a focus on the self (Arnett, 2000), these findings suggest that this time is certainly not a selfish time, as many emerging adults are actively oriented toward prosocial behaviors as indicated by mean levels of prosocial orientations (see Table 1). Indeed, recent research suggests that one of the most important criteria for adulthood cited among emerging adults is relational maturity, which reflects the value of social responsibility and highlights the importance of increasing one's ability to monitor oneself and to control one's impulses, with a focus on considering the needs and desires of others (Nelson et al., in press). The current findings extend this research by suggesting that even emerging adults who are in the midst of exploring their identities continue to be active in the pursuit of relational maturity by valuing the helping of others. Future research also should examine behavioral manifestations of prosocial orientations as a function of identity, as it is possible that commitment to beliefs and values might result in higher levels of prosocial behavior than does exploration alone.

\section{Positive orientations and gender}

The current study also examined and found a number of gender differences in terms of emerging adults' positive orientations. Namely, young men reported higher levels of public prosocial tendencies (the most self-oriented) and lower levels of altruistic (the least self-oriented) and emotional (prosocial behaviors motivated by the emotional nature of the situation) prosocial tendencies than did young women. These results are consistent with research on gender differences 
that document that (a) women in particular are attuned to relationships and the ethics of caring (Chodorow, 1989), and (b) self-construals differ by gender (Cross \& Madson, 1997). Specifically, men tend to have independent self-construals (i.e., more self-focused), whereas women tend to have interdependent self-construals (i.e., more relationship- or other-focused). Alternatively, these findings might suggest that there were only modest gender differences in prosocial behavior since neither public nor altruistic prosocial tendencies are related to more global prosocial behaviors (Carlo \& Randall, 2002). Although women typically report higher levels of empathy and sympathy, there are less consistent gender differences in actual prosocial reasoning or behaviors (Walker, 2006). Clearly, future work is needed to determine whether the few meaningful differences between prosocial tendencies for young men and young women are robust and practically significant. These findings also suggest utility in examining situation-specific prosocial tendencies, as more global measures of prosocial behaviors typically favor women, but the current study suggests that women are more likely to orient toward some types of prosocial behaviors (e.g., emotional), men are more likely to orient toward others (e.g., public), and there are no gender differences in still other orientations (e.g., dire).

That being said, there were consistent gender differences in the current study in regards to internalization of values and religiosity, with young women scoring higher than did young men on all levels of internalization of values, as well as on self-reported religiosity. Although inconsistent with research on the internalization of values during adolescence (Hardy et al., 2007), this is consistent with the mixed research on gender and prosocial development suggesting that positive internal traits tend to favor women; it should be noted that this is particularly pronounced for self-reported positive behaviors and traits, which could be a function of adherence to sociallyprescribed gender roles (Eisenberg, Spinrad, \& Sadovsky, 2006). Taken together, the current findings document some gender differences in select instances, but do not necessarily substantiate common perceptions (or misperceptions) that men are universally less prosocial or experience fewer positive orientations during emerging adulthood than do women (see Walker, 2006 for a review of gender differences in moral development), which is important to highlight given the negative picture that is often painted of emerging-adult men.

\section{Limitations and future directions}

The current study was not without limitations. First, although the sample was diverse in terms of geographical region, the sample consisted only of college students and was relatively homogeneous in terms of racial and ethnic diversity. As mentioned previously, critics of emerging adulthood purport that the characteristics emphasized by Arnett and others are largely culturally defined and may not apply to young people in different social, economic, cultural, and religious subgroups (Collins \& Madsen, 2006). However, a recent study (Nelson, 2007) suggests that even though individuals may not have the opportunity for exploration, it may still be a developmental task with important implications for healthy development. Because there have been very few studies examining emerging adults' behaviors in non-college, non-Western samples, it will be important for future research to examine more diverse populations in an attempt to understand the nature of exploration and experimentation during this developmental period more fully.

Second, although many significant findings existed concerning identity status, it is important to note the relatively low reliability of this measure. Moreover, the determination of identity status 
was sample specific, and thus relative given the homogeneity of the sample. Future research should utilize the full version of the identity scale (rather than the short form) as well as a more diverse sample of emerging adults in order to yield a more reliable and consequently valid assessment of their identity status. In addition, future work should examine variations in classification approaches (e.g., based upon median scores) to determine what is the most valid way of determining identity status. Also, the use of all self-report measures, as well as the use of the Internet to collect such measures may be seen as a limitation. Future work should incorporate other informants' evaluations of emerging adults' prosocial behaviors or tendencies to strengthen the internal validity of the study. Although a possible critique of online surveys is that participants may have limited access to the Internet, the use of Internet surveys among college populations may be just as effective, if not more effective, than using paper and pencil measures, given that nearly $100 \%$ of college students have access to the Internet (Stanton, 1998).

It is essential that future research be longitudinal to determine differentiating features of those who are identity-diffused in their early years of emerging adulthood, but who reach identity achievement by the end of this time period from those emerging adults who persist in their identity-diffused state. The present study's findings highlight the importance of intervention focusing on this potentially high-risk group of individuals who are more or less floundering during their emerging-adult years and likely to persist in an identity-diffused status. It will be important for future research to determine effective means of aiding both types of individuals in obtaining identity achievement. The substantial percentage of emerging adults who were classified as being identity-diffused in the current study (35\%) suggests that a period of identity diffusion may be relatively normative, and that interventions during adolescence or emerging adulthood aimed at increasing the exploration of positive tendencies and behaviors could be particularly useful for the minority of emerging adults who may experience extended identity diffusion. Future longitudinal work that discriminates between this normative identity-diffused group and those with extended identity diffusion is needed.

Despite these limitations, the current study makes several unique contributions to the literature. Primarily, findings suggest that characterizing emerging adulthood as a period of identity exploration includes exploration of both positive and negative behaviors. Given that prosocial behaviors and tendencies are common among emerging adults (e.g., Eisenberg et al., 2005), there is potential utility in research and intervention focusing on ways in which to foster successfully the prosocial orientations typical of this age group. The current study is an important first step in looking on the bright side of a time of life that is not only characterized by risk taking and substance use, but also by the consideration of the needs and desires of others and the establishment of social responsibility through the fostering of positive orientations.

\section{Acknowledgement}

The authors express appreciation to the instructors and students at all Project READY data collection sites for their assistance. We also are grateful for the grant support of the Family Studies Center at Brigham Young University, as well as the junior faculty sabbatical grant given to the second author by Loyola College in Maryland. 


\section{References}

Arnett, J. J. (2000). Emerging adulthood: A theory of development from the late teens through the twenties. American Psychologist, 55, 469-480.

Arnett, J. J., \& Jensen, L. A. (2002). A congregation of one: Individualized religious beliefs among emerging adults. Journal of Adolescent Research, 17, 451-467.

Balistreri, E., Busch-Rossnagel, N. A., \& Geisinger, K. F. (1995). Development and preliminary validation of the ego identity process questionnaire. Journal of Adolescence, 18, 179-192.

Barry, C. M., \& Nelson, L. J. (2005). The role of religion in the transition to adulthood for young emerging adults. Journal of Youth and Adolescence, 34, 245-255.

Bishop, D. I., Macy-Lewis, J. A., Schnekloth, C. A., Puswella, S., \& Struessel, G. L. (1997). Ego identity status and reported alcohol consumption: A study of first-year college students. Journal of Adolescence, 20, 209-218.

Carlo, G., Hausmann, A., Christiansen, S., \& Randall, B. A. (2003). Sociocognitive and behavioral correlates of a measure of prosocial tendencies for adolescents. Journal of Early Adolescence, 23, 107-134.

Carlo, G., \& Randall, B. A. (2002). The development of a measure of prosocial behaviors for late adolescents. Journal of Youth and Adolescence, 31, 31-44.

Carroll, J. S., Willoughby, B., Badger, S., Nelson, L. J., Madsen, S. D., \& Barry, C. M. (2007). So close, yet so far away: The impact of varying marital horizons on emerging adulthood. Journal of Adolescent Research, 22, 219-247.

Chodorow, N. (1989). Feminism and psychoanalytic theory. New Haven, CT: Yale University Press.

Collins, W. A., \& Madsen, S. D. (2006). Personal relationships in adolescence and early adulthood. In D. Perlman, \& A. Vangelisti (Eds.), The Cambridge handbook of personal relationships (pp. 191-209). New York: Cambridge University Press.

Cross, S. E., \& Madson, L. (1997). Models of the self: Self-construals and gender. Psychological Bulletin, 122, 5-37.

Eisenberg, N., Cumberland, A., Guthrie, I. K., Murphy, B. C., \& Shepard, S. A. (2005). Age changes in prosocial responding and moral reasoning in adolescence and early adulthood. Journal of Research on Adolescence, 15, 235-260.

Eisenberg, N., \& Fabes, R. A. (1998). Prosocial development. In: W. Damon (Series Ed.), N. Eisenberg (Vol. Ed.), Handbook of child psychology, Vol. 3: Social, emotional, and personality development (5th ed., pp. 701-778). New York: Wiley.

Eisenberg, N., Spinrad, T., \& Sadovsky, A. (2006). Empathy-related responding in children. In M. Killen, \& J. G. Smetana (Eds.), Handbook of moral development (pp. 517-550). Mahwah, NJ: Erlbaum.

Erikson, E. H. (1968). Identity: Youth and crisis. New York: Norton.

Fabes, R. A., Carlo, G., Kupanoff, K., \& Laible, D. (1999). Early adolescence and prosocial/moral behavior I: The role of individual processes. Journal of Early Adolescence, 19, 5-16.

Facio, A., \& Micocci, F. (2003). Emerging adulthood in Argentina. In J. J. Arnett, \& N. L. Galambos (Eds.), New directions in child development: Exploring cultural conceptions of the transition to adulthood, No. 100 (pp. 21-31). San Francisco: Jossey-Bass.

Fulton, A. S. (1997). Identity status, religious orientation, and prejudice. Journal of Youth and Adolescence, 26, 1-11.

Gallup, G., Jr., \& Lindsay, D. M. (1999). Surveying the religious landscape: Trends in US beliefs. Harrisburg, PA: Morehouse.

Grolnick, W. S., Deci, E. L., \& Ryan, R. M. (1997). Internalization within the family: The self-determination theory perspective. In J. E. Grusec, \& L. Kuczynski (Eds.), Parenting and children's internalization of values: A handbook of contemporary theory (pp. 135-161). Hoboken, NJ: Wiley.

Hardy, S. A., \& Carlo, G. (2005). Religiosity and prosocial behaviors in adolescence: The mediating role of prosocial values. Journal of Moral Education, 34, 231-249.

Hardy, S. A., Padilla-Walker, L. M., \& Carlo, G. (2007). Parenting styles and adolescents' internalization of moral values, submitted for publication.

Kiesling, C., Sorell, G. T., Montgomery, M. J., \& Colwell, R. K. (2006). Identity and spirituality: A psychosocial exploration of the sense of spiritual self. Developmental Psychology, 42, 1269-1277.

Koenig, H. G., McCullough, M. E., \& Larson, D. B. (2001). Handbook of religion and health. New York: Oxford University Press. 
Kroger, J. (2000). Identity development: Adolescence through adulthood. Thousand Oaks, CA: Sage.

Lewis, C. A., Shevlin, M., McGuckin, C., \& Navrátil, M. (2001). The Santa Clara Strength of Religious Faith QUestionnaire: Confirmatory factor analysis. Pastoral Psychology, 49, 379-384.

Marcia, J. E. (1966). Development and validation of ego-identity status. Journal of Personality and Social Psychology, 3, 551-558.

Mayseless, O., \& Scharf, M. (2003). What does it mean to be an adult? The Israeli experience. In J. J. Arnett, \& N. L. Galambos (Eds.), New directions in child development: Exploring cultural conceptions of the transition to adulthood, No. 100 (pp. 5-20). San Francisco: Jossey-Bass.

McKinney, J. P., \& McKinney, K. G. (1999). Prayer in the lives of late adolescents. Journal of Adolescence, 22, 279-290.

Neitz, M. J. (1995). Feminist theory and religious experience. In R. W. Hood Jr. (Ed.), Handbook of religious experience (pp. 520-534). Birmingham, AL: Religious Education Press.

Nelson, L. J. (2007). Perceived status on adulthood, adult roles, and culture: An examination emerging adulthood in Romania, submitted for publication.

Nelson, L. J., Badger, S., \& Wu, B. (2004). The influence of culture in emerging adulthood: Perspectives of Chinese college students. International Journal of Behavioral Development, 28, 26-36.

Nelson, L. J., \& Barry, C. M. (2005). Distinguishing features of emerging adulthood: The role of self-classification as an adult. Journal of Adolescent Research, 20, 242-262.

Nelson, L. J., Padilla-Walker, L. M., Carroll, J. S., Madsen, S. D., Barry, C. M., \& Badger, S. (in press). "If you want me to treat you like an adult, start acting like one!" Comparing the criteria that emerging adults and their parents have for adulthood. Journal of Family Psychology.

Padilla-Walker, L. M. (2005). Perceived appropriateness and accurate perception of parental messages as predictors of adolescents' internalization of values and behaviors. Dissertation Abstracts International: Section B: The Sciences and Engineering, 66, 1199.

Padilla-Walker, L. M., \& Carlo, G. (in press). Personal values as a mediator between parent and peer expectations and adolescent behaviors. Journal of Family Psychology.

Pedersen, D. M., Williams, R. N., \& Kristensen, K. B. (2000). The relation of spiritual self-identity to religious orientations and attitudes. Journal of Psychology and Theology, 28, 138-148.

Ryan, R. M., \& Connell, J. P. (1989). Perceived locus of causality and internalization: Examining reasons for acting in two domains. Journal of Personality and Social Psychology, 57, 749-761.

Sanders, J. L. (1998). Religious ego identity and its relationship to faith maturity. Journal of Psychology: Interdisciplinary and Applied, 132, 653-658.

Saroglou, V., Pichon, I., Trompette, L., Verschueren, M., \& Dernelle, R. (2005). Prosocial behavior and religion: New evidence based on projective measures and peer ratings. Journal for the Scientific Study of Religion, 44, 323-348.

Schulenberg, J., O’Malley, P. M., Bachman, J. G., \& Johnston, L. D. (2005). Early adult transitions and their relation to well-being and substance use. In R. A. Settersten Jr., F. F. Furstenberg Jr., \& R. G. Rumbaut (Eds.), On the frontier of adulthood: Theory, research, and public policy (pp. 427-453). Chicago: The University of Chicago Press.

Schulenberg, J. E., \& Zarrett, N. R. (2006). Mental health during emerging adulthood: Continuity and discontinuity in courses, causes, and function. In J. J. Arnett, \& J. L. Tanner (Eds.), Emerging adults in America: Coming of age in the 21 st century (pp. 135-172). Washington, DC: American Psychological Association.

Stanton, J. M. (1998). An empirical assessment of data collection using the Internet. Personnel Psychology, 51, 709-725.

Walker, L. J. (2006). Gender and morality. In M. Killen, \& J. G. Smetana (Eds.), Handbook of moral development (pp. 93-115). Mahwah, NJ: Erlbaum.

Welton, G. L., \& Houser, M. D. (1997). Ego identity and drug experimentation: The fable of the arrested abstainer. Counseling and Values, 41, 219-234.

Willemsen, E. W., \& Waterman, K. K. (1991). Ego identity status and family environment: A correlational study. Psychological Reports, 69, 1203-1212.

Zaleski, E. H., \& Schiaffino, K. M. (2000). Religiosity and sexual risk-taking behavior during the transition to college. Journal of Adolescence, 23, 223-227. 